\title{
Insulin-Related Growth Factors Stimulate Proliferation of Retinal Progenitors in the Goldfish
}

\author{
SHAYNE-E MILE M. BOUCHER ${ }^{3}$ AND PETER F. HITCHCOCK ${ }^{1,2,3 *}$ \\ ${ }^{1}$ Department of Ophthalmology, The University of Michigan, Ann Arbor, Michigan 48105 \\ 2Department of Anatomy and Cell Biology, The University of Michigan, \\ Ann Arbor, Michigan 48105 \\ ${ }^{3}$ The Neuroscience Program, The University of Michigan, Ann Arbor, Michigan 48105
}

\begin{abstract}
The retina of the adult goldfish grows throughout the life of the animal, in part, by the continual addition of new neurons. Further, destruction of extant neurons in this tissue stimulates neuronal regeneration. In an attempt to identify growth factors that regulate both normal and injury-stimulated neurogenesis, we used organ culture techniques and tested nine peptide growth factors for their ability to modulate cell proliferation in both normal retinas and retinas with lesions. Of the growth factors tested, only the insulin-related peptides (insulin and insulin-like growth factors I and II) consistently stimulated proliferation, and this was restricted to the retinal progenitors within the circumferential germinal zone. N one of the growth factors tested stimulated proliferation of rod precursors (cells in the mature retina whose progeny are exclusively rod photoreceptors) or the injury-stimulated retinal progenitors. Although the negative data are subject to multiple interpretations, these data suggest that in the retina of the adult goldfish, insulin-related peptides regulate proliferation of retinal progenitors within the circumferential germinal zone, but molecules that modulate the proliferation of the rod precursors or injury-induced retinal progenitors in the retina of the adult goldfish have yet to be identified. J . Comp. Neurol. 394:386-394, 1998. @ 1998 Wiley-Liss, Inc.
\end{abstract}

Indexing terms: teleost fish; IGF-I; IGF-II; organ culture; regeneration

The retina of the adult goldfish is a useful model to study both neuronal devel opment and the response of the central nervous system (CNS) to injury. This tissuegrows throughout the life of the animal, and injuries that destroy existing neurons are repaired by injury-stimulated neurogenesis. New neurons are continually added to the retina of the goldfish from two spatially separate pools of progenitors (J ohns, 1977; Meyer 1978; J ohns and Fernald, 1981). First, at the extreme margin, an annulus of retinal progenitors, known as the circumferential germinal zone (CGZ), gives rise to annuli of all retinal cell types. Second, scattered throughout the outer nuclear layer of the extant retina are neuronal progenitors, known as rod precursors, which give rise exclusively to rod photoreceptors that are insinuated into the existing lawn of mature photoreceptors. Lesions that destroy a sufficient number of existing neurons stimulate the appearance of a third population of retinal progenitors (see recent reviews, Hitchcock and Raymond, 1992; Raymond and Hitchcock, 1997), which give rise to regenerated neurons. Evidence to date indicates that the rod precursors are the antecedents of the injury-induced retinal progenitors (Raymond et al., 1988;
Hitchcock et al., 1992), although a contribution from other cell types remains a possibility (Raymond and Hitchcock, 1997).

In an attempt to identify molecules that regulate both the ongoing and injury-stimulated neurogenesis in the retina of the goldfish, we developed an organ-culture technique to test the ability of various peptide growth factors to modulate proliferation of retinal progenitors. Candidate growth factors were selected on the basis of their known mitogenic effects on neuroepithelial cells in the brain and retina (e.g., Anchan et al., 1991; Lillien and Cepko, 1992; Mack and Fernald, 1993; Anchan and Reh, 1995; Hernández-Sánchez et al., 1995; Frade et al., 1996), and their activation of intracellular signaling pathways

Grant sponsor: NIH; Grant numbers: EY07060 and EY07003 (CORE Grant).

*Correspondence to: Peter Hitchcock, Ph.D., W.K. Kellogg Eye Center, University of Michigan, 1000 Wall Street, Ann Arbor, MI 48105.

E-mail:peterh@umich.edu

Received 18 August 1997; Revised 23 December 1997; Accepted 30 December 1997 
via cell-surface, tyrosine kinase receptors. Each growth factor was tested on both normal retinas and retinas with lesions. I n addition, two growth factors, insulin-like growth factor I (IGF-I) and basic fibroblast growth factor (FGF-2) were tested in combination on retinas with lesions.

The results of this study showed that only insulinrelated factors (insulin, IGF-I, and IGF-II) consistently modulated proliferation, and this was limited to the retinal progenitors of the CGZ. The mitotic activity of the rod precursors and the injury-induced retinal progenitors was not stimulated by any of the growth factors tested. Based upon these data, we hypothesize that insulin-related growth factors are present in the retina of the goldfish, their activity is mediated by their respective receptors, and together these molecules regulate the ongoing, growthassociated neurogenesis in this tissue.

Portions of the data reported here were presented in preliminary form (Boucher and Hitchcock, 1994a,b, 1995).

\section{MATERIALS AND METHODS Animals}

J uvenile goldfish (Carassi us auratus), 3-4 cm standard length, were purchased from local pet stores and housed for at least 1 week before performing experiments. Prior to surgery and euthanasia, fish were anesthetized in tricaine methanesulfonate (MS222, Sigma, St. Louis, MO). All animals were killed by exsanguination. All protocols used in this study were approved by the University of Michigan Committee for the Use and Care of Animals.

\section{Preparation of eyecups and organ culture protocol}

Eyes were enucleated and bathed for a minimum of 5 minutes in a 1:10 dilution of Antibiotic-Antimycotic solution (GIBCO/BRL Life Technologies, Grand I sland, NY) in phosphate-buffered saline; during this time the conjunctiva and extraocular muscles were trimmed from the globe. Eyes were transferred to a petri dish, and the lens, cornea, and part of the iris epithelium were removed. The diameter of each lens was measured. After three rinses each in sterile phosphate-buffered saline, $\mathrm{pH}$ 7.4, and Media 199 (M199, HEPES modification; Sigma) supplemented with $20 \mathrm{mg} / \mathrm{ml}$ gentamicin (Sigma), each eyecup was placed into an uncoated well of a 24 well tissue culture plate, vitreous chamber facing up, and $2 \mathrm{ml}$ of M 199 was added, either alone or supplemented with a growth factor to be tested. Culture plates were placed in an air-tight box containing $95 \% \mathrm{O}_{2} / 5 \% \mathrm{CO}_{2}$ and continuously agitated on a rotating table for three days at room temperature. The media and oxygenated air were changed daily. On the second day, $5 \mu \mathrm{l}$ of $2 \mathrm{mM}$ bromodeoxyuridine (BrdU; Sigma), a thymidine analog and a marker for cells synthesizing DNA, was added to each well, and the eyecups were incubated for an additional 16-18 hours. On the third day, the experiment was terminated and the eyecups were processed for BrdU immunocytochemistry (see below).

\section{Ocular/retinal lesions}

Fish were anesthetized in MS222, and a full-thickness cut was made with a microknife parallel to the limbus in the dorsonasal quadrant of each eye. The incision was 300-500 $\mu \mathrm{m}$ from the scleral-corneal junction, which is the
TABLE 1. Growth Factors Tested and Their Concentrations ${ }^{1}$

\begin{tabular}{ll}
$\begin{array}{l}\text { Growth } \\
\text { factor }\end{array}$ & \multicolumn{1}{c}{ Concentrations tested } \\
\hline IGF-I & $1.0 \mathrm{nM}, 2.67 \mathrm{nM}, 10.0 \mathrm{nM}, 13.4 \mathrm{nM}, 26.7 \mathrm{nM}, 15.0 \mathrm{nM}^{*}, 25.0 \mathrm{nM} *$ \\
IGF-II & $1.0 \mathrm{nM}, 10.0 \mathrm{nM}, 100.0 \mathrm{nM}, 25.0 \mathrm{nM} *$ \\
insulin & $1.0 \mathrm{nM}, 10.0 \mathrm{nM}, 0.83 \mu \mathrm{M}, 4.2 \mu \mathrm{M}, 8.3 \mu \mathrm{M}, 25.0 \mathrm{nM}^{*}$ \\
FGF-1 & $25 \mathrm{nM} *$ \\
FGF-2 & $1.2 \mathrm{nM}, 6.0 \mathrm{nM}, 10 \mathrm{nM}, 12.2 \mathrm{nM}, 7.5 \mathrm{nM}^{*}, 25.0 \mathrm{nM}^{*}$ \\
EGF & $0.32 \mathrm{nM}, 3.2 \mathrm{nM}, 32.0 \mathrm{nM}, 25.0 \mathrm{nM}^{*}$ \\
PDGF-B & $0.1 \mathrm{nM}, 1.0 \mathrm{nM}, 10.0 \mathrm{nM}, 25.0 \mathrm{nM}^{*}$ \\
NGF & $0.1 \mathrm{nM}, 1.0 \mathrm{nM}, 10.0 \mathrm{nM}, 25.0 \mathrm{nM}^{*}$ \\
NT-3 & $0.1 \mathrm{nM}, 1.0 \mathrm{nM}, 10.0 \mathrm{nM}, 25.0 \mathrm{nM}^{*}$ \\
\hline
\end{tabular}

${ }^{1}$ Asterisks indicate concentrations tested with retinas with lesions. With the exception of F GF-1, each growth factor was tested at a minimum of four different concentrations in at least two separate, independently controlled experiments. Note that insulin was also tested in the micromolar range. IGF-I, insulin-like growth factor I; IGF-II, insulin-like growth factor II; FGF-1, fibroblast growth factor 1; FGF-2, fibroblast growth factor 2; EGF, epidermal growth factor; PDGF-B, platelet-derived growth factor-B; NGF, nerve growth factor; NT-3, neurotrophin 3.

approximate location within the retina of the CGZ. These animals survived 1 week post-lesion to allow a blastema of injury-induced retinal progenitors to form along the margin of the retinal wound (see Hitchcock et al., 1992). These eyes were then prepared for the organ culture as described above.

\section{Growth factors and biochemicals}

Table 1 lists the growth factors and the concentrations that were tested. All growth factors were purchased from Austral Biologicals (San Ramon, CA), with the exception of insulin (Sigma) and insulin-like growth factor-II (R \& D Systems, Minneapolis, MN). Each growth factor was either a human-recombinant peptide or isolated from bovine tissues.

\section{Incubation conditions}

Thirteen independently controlled experiments (40 incubation conditions; see Table 1) were performed. In experiments with normal retinas, three eyecups were used in each incubation condition; in experiments with retinas with lesionsl esioned retinas, six eyecups were used in each incubation condition. In eight experiments with normal retinas, three different molar concentrations of each growth factor, generally spanning either a 10 -fold range $(1 \times, 5 \times$, $10 \times)$ or 100 -fold range $(1 \times, 10 \times, 100 \times)$, were tested. In one additional experiment, insulin and IGF-I were tested on normal retinas at two concentrations, 1.0 and $10.0 \mathrm{nM}$. In three experiments with retinas with lesions, a single high molar concentration ( $25 \mathrm{nM})$ of each growth factor was tested. (Three factors were tested in each experiment. In experiments in which IGF-I was not tested directly, it was included in an additional incubation condition as a positive control.) In a final experiment with retinas with lesions, IGF-I and FGF-2 were tested separately and in combination to evaluate their potential synergistic effects. For each of the 13 experiments, at least three control eyes were incubated in M-199 alone and analyzed in parallel (see bel ow). F or each of the 40 incubation conditions (Table 1), BrdU + cells were counted in sections from a minimum of three eyecups, with the exception of two incubation conditions, $2.6 \mathrm{nM}$ IGF-I and 10nM IGF-I, where cells were counted in sections from two eyecups only.

\section{BrdU I mmunocytochemistry}

Eyecups were fixed in 4\% paraformaldehyde in $100 \mathrm{mM}$ phosphate buffer, pH 7.4, for at least 1 hour and infiltrated in a graded series of sucrose/phosphate buffer solutions, 
from $5 \%$ to $20 \%$. The eyecups were then infiltrated in a 2:1 solution of $20 \%$ sucrose/O.C.T. (TissueTek, Miles Inc., Elkhart, IN), frozen, and stored at $-80^{\circ} \mathrm{C}$. Eyecups were sectioned at $10 \mu \mathrm{m}$ on a cryostat, and every other section was mounted onto a poly-L-lysine-coated slide. Sections were immunostained with an anti-BrdU monoclonal antibody (Becton-Dickinson, San J ose, CA) according to Hitchcock et al. (1992), in combination with a secondary antibody conjugated to tetramethylrhodamine isothiocyanate (TRITC). Sections were counterstained with $0.0001 \%$ bisbenzimide, a fluorescent nudlear stain. Slides were coverslipped with Gel/Mount (Biomeda Corp., Foster City, CA) and inspected and photographed by using indirect fluorescence microscopy.

\section{Sectioning the eyecups and counting B rdU-labeled cells}

Eyecups were sectioned in a plane that passed approximately parallel to the dorsonasal-ventrotemporal axis of the eye. By using formulas from solid geometry and the relationship between lens diameter and retinal length (see E aster et al., 1977), a "safety zone" was estimated for each eyecup wherein sections would be predicted to pass orthogonal to the retinal layers, thereby avoiding systematic errors introduced by counting cells in sections cut obliquely through the retina. For normal retinas, BrdU ${ }^{+}$cells were counted only in sections that came from within the "safety zone." For retinas with lesions, an additional constraint was imposed, whereby BrdU ${ }^{+}$cells were counted only in sections that fell within the "safety zone" and passed through the center of the lesion. We chose not to use an unbiased method for estimating the number of BrdU ${ }^{+}$cells in each section, because, 1) we were interested only in the relative, not absolute, number of $\mathrm{BrdU}^{+}$cells in retinas treated with different growth factors, and 2) we were comparing identical populations of cells in the different retinas.

Preliminary experiments determined that within a retina, the variance in the average number of BrdU + cells per section fell to a constant value when the number of sections counted and averaged exceeded 15 . We viewed this as the minimum number of sections needed to provide an accurate estimate of theaverage number of label ed cells per section from any given retina. Therefore, we counted $\mathrm{BrdU}^{+}$cells in a minimum of 20 sections per eyecup (60 sections per incubation condition). I n sections from normal retinas, BrdU + cells were counted in four areas: 1) the dorsonasal CGZ, 2) a $300 \mu \mathrm{m}$ length of mature neural retina (MNR) adjacent to, but not abutting, CGZ, 3) the ventrotemporal MNR (the opposite side of the section, opposite pole of the eye), and 4) the ventrotemporal CGZ. (Because there were no differences in the average number of $\mathrm{BrdU}+$ cells in dorsal vs. ventral retina, for purposes of illustration only, these data were combined [see Results]). The central boundary of the CGZ was defined as the site where the retinal layers first appear, and the peripheral boundary of the CGZ was identified as the transition from the multilayered neuroepithelium to the single-cell thick iris epithelium. In retinas with lesions, BrdU + cells were counted in five locations, with sites adjacent to the injuryinduced blastema designated as "proximal "and sites at the opposite pole of the eye designated as "distal:" 1) proximal CGZ, 2) proximal MNR, 3) blastema, 4) distal MNR, and 5) distal CGZ. The blastema was identified as the area lying immediately adjacent to the margin of the retinal lesion that contained elongated, neuroepithelial cells that were
$\mathrm{BrdU}^{+}$(see Hitchcock et al., 1992). In both normal and retinas with lesions, BrdU + cells were observed within the iris epithelium, but not included in the cell counts. For each retina, the average number of $\mathrm{BrdU}^{+}$cells per section (within each of the areas described above) was computed. Averages for each retina tested under the same condition were combined, and the mean and standard error calculated. Within each experiment, the average number of $\mathrm{BrdU}^{+}$cells per section in control and treated groups were statistically compared by using a one-way ANOVA. Pairwise comparisons using a Scheffe test were evaluated if the overall level of significance was 0.05 or less.

\section{Illustrations}

Col or photographs weretaken of representative immunostained sections, and the photographic slides were digitized. For purposes of illustration, images were converted to gray scale by using Adobe Photoshop and printed with a Kodak ds 8650 color printer.

\section{RE SULTS \\ Proliferation persists in defined basal media}

Incubation of normal eyecups in M199 alone was sufficient to keep the retina intact and sustain proliferation of retinal progenitors (Fig. $1 A, B$ ).

In eyecups incubated for 3 days in M199 alone, the morphology of the cellular and synaptic layers in the peripheral third of the retina appeared normal; the neuroepithelial cells of the CGZ were packed closely together and the retinal pigmented epithelium (RPE) remained closely apposed to the photoreceptor layer. Within the central retina, in contrast, the lamination was somewhat disrupted, and the RPE retracted from the photoreceptors. Our assumption is that the disruption of the more central regions of the retina are due to the relatively poor diffusion of nutrients there, perhaps resulting from the greater thickness of central retina or the residual layer of vitreous that could not be completely removed. Despite some degradation of retinal morphology centrally, when the eyecups were incubated in M199 alone cells within the CGZ and the adjacent MNR incorporated BrdU, and the average number of these BrdU ${ }^{+}$cells was quantitatively similar to retinas labeled with BrdU in vivo and allowed to survive a similar length of time (Fig. 2A).

\section{Proliferation in the normal retina stimulated by insulin-related growth factors}

Of the growth factors tested (Table 1), only insulin, IGF -I and, at high concentrations, I GF - II stimulated proliferation, and this response was limited to the neuroepithelial cells of the CGZ (Figs. 1C, 2A; Table 2).

Qualitatively, in sections from retinas treated with insulin or IGF-I at concentrations of $10 \mathrm{nM}$ or higher (Fig. 1C), the CGZ was markedly enlarged and contained many more $\mathrm{BrdU}^{+}$cells than in control retinas. In all other respects, the morphology of theretinas treated with insulinrelated peptides was similar to those incubated in M199 alone. For retinas treated with insulin (data not shown) and IGF-I (Fig. 2B), the number of BrdU ${ }^{+}$cells in the CGZ was dose dependent. I ncreasing the concentration of I GF -I from 2.67 to 13.4 to $26.67 \mathrm{nM}$ increased the number of $\mathrm{BrdU}^{+}$cells in the CGZ by three, seven-, and 11-fold, respectively, over control values. When tested at the same 

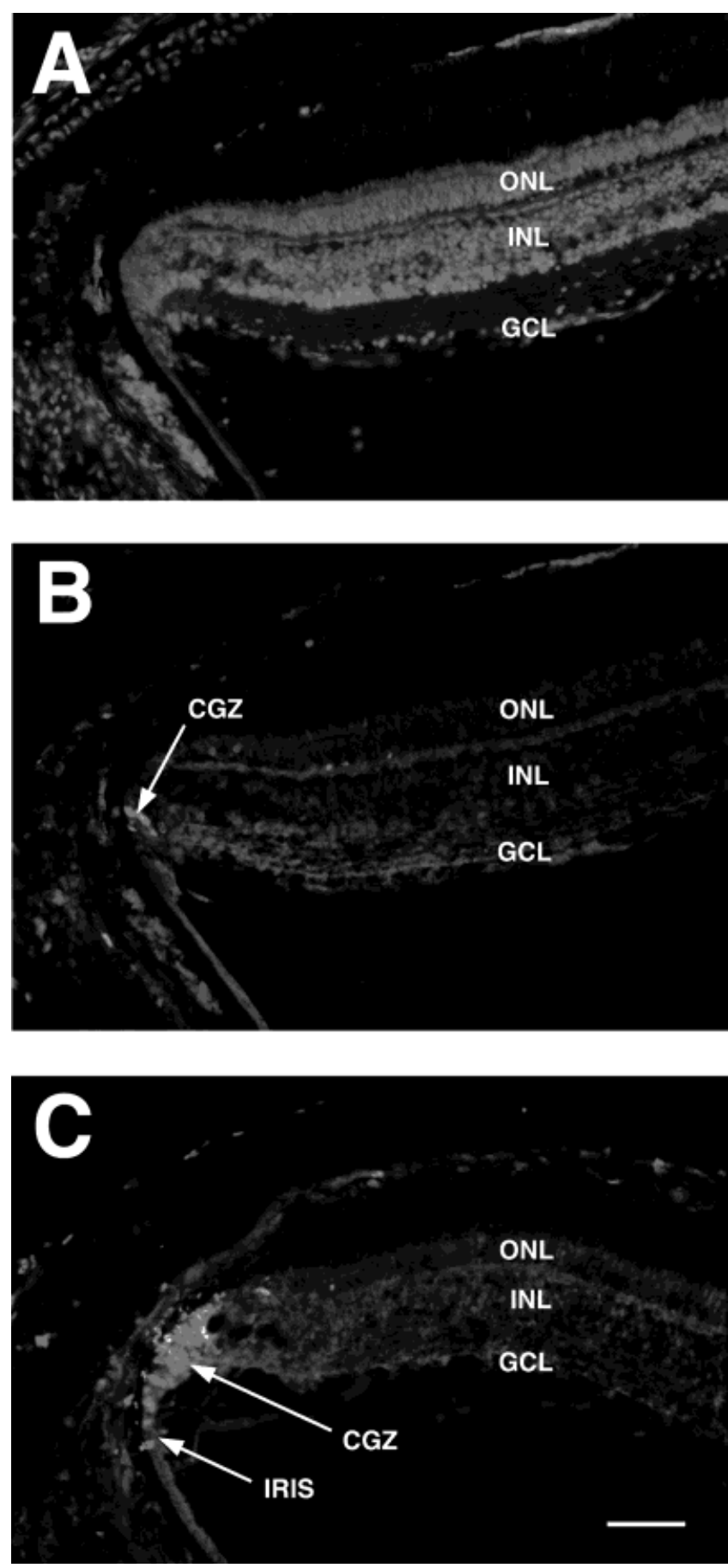

Fig. 1. Low magnification, fluorescence photomicrographs of sections taken from eyecups incubated for 3 days in $M-199$ al one $(A, B)$ or M-199 plus $10 \mathrm{nM}$ insulin-like growth factor I (IGF-I; C). A: Bisbenzimide-stained section. B: The same section as in A, illuminated with a filter set to reveal the tetramethyl rhodamine isothiocyanate(TRITC) labeled, bromodeoxyuridine positive $\left(\mathrm{BrdU}^{+}\right)$cells in the circumferential germinal zone (CGZ; arrow). C: A section taken from an eyecup treated with $10 \mathrm{nM}$ of IGF-I. Note the normal morphology of the retina and the $\mathrm{BrdU}^{+}$cells in the CGZ (A and $\left.\mathrm{B}\right)$. Note also the increased number of $\mathrm{BrdU}^{+}$cells in the CGZ (cf. B and C), and the presence of $\mathrm{BrdU}^{+}$cells in the iris epithelium. ONL, outer nuclear layer; INL, inner nuclear layer; GCL, ganglion cell layer; CGZ, circumferential germinal zone; IRIS, iris epithelium. Scale bar $=50 \mu \mathrm{m}$. concentration, IGF-I was more potent than insulin (Fig. 2A) or IGF-II, although for both IGF-I and insulin, concentrations as low as $1 \mathrm{nM}$ produced a noticeable increase in the number of $\mathrm{BrdU}^{+}$cells in the CGZ (data not shown). Only relatively high concentrations ( $25 \mathrm{nM}$ ) of IGF-II significantly increased the number of BrdU + cells within the CGZ (Table2). In contrast to the robust proliferation of cells in the CGZ stimulated by the insulin-related factors, these molecules did not stimulate proliferation of cells within the MNR. Because the mitotically active cells within the MNR are predominantly rod precursors, these data suggest that unlike the neuroepithelial cells of the CGZ, this population of progenitors is not responsive to insulin-related molecules (Fig. 2A,B). Although not examined quantitatively, both insulin and IGF-I increased the number of $\mathrm{BrdU}^{+}$cells in the iris epithelium and sclera.

All the noninsulin-related factors tested failed to stimulate proliferation of mitotically active cells (e.g., Fig. 2A; Table 2). Qualitatively, retinas treated with these factors incorporated BrdU, and the morphology of the retina and CGZ was similar to that in eyecups incubated in media alone or the insulin-related molecules. Eyecups treated with FGF-2 did, however, contain a noticeably greater number of $\mathrm{BrdU}^{+}$cells in the sclera than eyecups incubated in M-199 al one (data not shown), indicating that the lack of response by the retinal progenitors was not due to the inability of mammalian FGF-2 to stimulate proliferation of teleost cells (see Discussion).

\section{Proliferation stimulated by growth factors in retinas with lesions matches that seen in normal retinas}

Incubation of retinas with lesions in M199 alone, as for the normal eyecups, was sufficient to keep the retina intact and sustain proliferation within the CGZ, MNR, and injury-induced blastema (Fig. 3).

Similar to retinas with lesions labeled with BrdU in vivo, there were more BrdU + cells in the proximal CGZ and the proximal MNR, areas adjacent to the lesion, than in the distal CGZ and distal MNR (Fig. 4). This results from proliferation in vivo stimulated by the injury prior to culturing the retinas (see Raymond et al., 1988; Henken and Yoon, 1989; Hitchcock et al., 1992). The blastema was consistently present in the retinas with lesions, but the number of $\mathrm{BrdU}+$ cells there varied from eyecup to eyecup as well as from section to section within the same eyecup. Again, the number of $\mathrm{BrdU}^{+}$cells in the retinas with lesions incubated in M199 alone approximated that observed in retinas with lesions that were labeled with BrdU in vivo (Fig. 4).

As for normal retinas, only the insulin-related factors stimulated proliferation in retinas with lesions (Fig. 4; Table 2), and this again was limited to the retinal progenitors within the CGZ. Insulin, IGF-I and IGF-II at a concentration of $25 \mathrm{~nm}$ (Table 1) robustly stimulated proliferation of cells in both the proximal and distal CGZ (Figs. 3 and 4; Table 2). In contrast, none of the growth factors tested stimulated proliferation of rod precursors in the MNR or injury-induced retinal progenitors in the blastema (Fig. 4; Table 2).

In two culture conditions, 25 nM FGF-1 and FGF-2, the retinas with lesions displayed a small, but statistically significant decrease in the number of BrdU + cells, but this was limited to the MNR, and only the MNR distal to the lesion (Fig. 4; Table 2). These were the only instances, from a total of five separate experiments with either F GF-1 or -2 


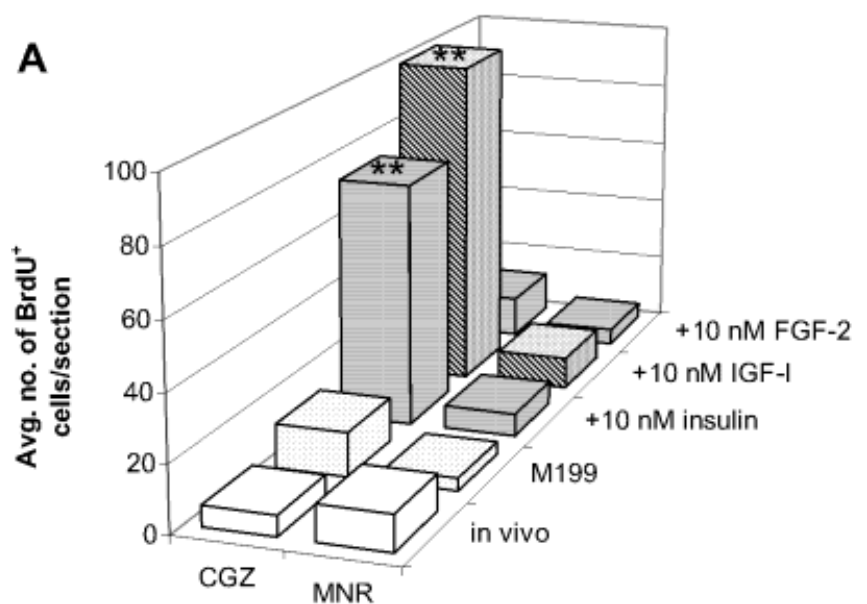

Fig. 2. Histograms illustrating the average number of bromodeoxyuridine positive $\left(\mathrm{BrdU}^{+}\right)$cells per section. $\mathbf{A}$ : Illustrates the average number of $\mathrm{BrdU}^{+}$cells in eyes that were exposed to BrdU in vivo and processed 3 days later, and eyes incubated for 3 days in M-199 alone, $10 \mathrm{nM}$ insulin, $10 \mathrm{nM}$ insulin-like growth factor I (IGF-I) and, as an

TABLE 2. Summary of Results From Testing Growth Factors on Normal

\begin{tabular}{|c|c|c|c|c|c|}
\hline & $\begin{array}{l}\text { CGZ } \\
\text { pCGZ }\end{array}$ & $\begin{array}{c}\text { MNR } \\
\text { pMNR }\end{array}$ & BL & dMNR & dCGZ \\
\hline \multirow[t]{2}{*}{ IGF-I } & $+($ all) & * & & & \\
\hline & $+(15,25)$ & * & * & * & $+(15,25)$ \\
\hline insulin & $\begin{array}{l}+ \text { (all) } \\
+(25)\end{array}$ & $\begin{array}{l}* \\
*\end{array}$ & $*$ & * & $+(25)$ \\
\hline \multirow[t]{2}{*}{ |GF-II } & $+(\geq 25)$ & * & & & \\
\hline & $+(25)$ & * & * & * & $+(25)$ \\
\hline \multirow{2}{*}{$\begin{array}{l}\text { FGF-1 } \\
\text { FGF-2 }\end{array}$} & $*$ & * & * & $-(25)$ & $*$ \\
\hline & * & * & & & \\
\hline \multirow{2}{*}{ EGF } & * & * & * & $-(25)$ & $*$ \\
\hline & * & * & * & * & * \\
\hline PDGF-B & * & * & & & \\
\hline \multirow{2}{*}{ NGF } & $*$ & * & F & T & \\
\hline & * & * & * & * & * \\
\hline NT-3 & $\begin{array}{l}* \\
*\end{array}$ & $\begin{array}{l}* \\
*\end{array}$ & $*$ & $*$ & $*$ \\
\hline
\end{tabular}

${ }^{1} \mathrm{~A}$ plus sign indicates a statistically significant increase in the number of BrdU + cells $(P<0.05)$. A minus sign indicates a statistically significantly decrease in the number of $\mathrm{BrdU}^{+}$cells $(\mathrm{P}<0.05)$. An asterisk indicates nostatistically significant change $(P>0.05)$. The concentrations, in $\mathrm{nM}$, at which significant results were observed are in parentheses (cf. Tables 1 and 2). CGZ and MNR represent the areas sampled in normal retinas; pCGZ, pMNR, BL, dMNR, and dCGZ represent the areas sampled in retinas with lesions (see text). In the two left-most columns, the upper (italicized) values (CGZ, MNR) indicate results for normal retinas, whereas the lower values represent results for retinas with lesions. IGF-I, I nsulin-like growth factor I; IGF-II, insulin-like growth factor II: FGF-I, fibroblast growth factor 1; FGF-2, fibroblast growth factor 2: EGF, epidermal growth factor; PDGF-B, platelet-derived growth factor-B; NGF, nerve growth factor; NT-3, neurotrophin 3 .

(Table 1; see below), where we observed a significant result. Our bias is to interpret these two data points as aberrations, largely because of the small average number of BrdU + cells in the MNR and the inherent variability in these data. The possibility certainly remains, however, that the FGFs do modulate proliferation of the mitotically active cells in the goldfish retina, and the culture conditions and/or growth factor concentrations were not optimal for consistently revealing these effects.

\section{G F - I and F GF -2 do not act synergistically}

Previous studies have demonstrated that some mitotically competent cells proliferate in response to a combination of growth factors (e.g., Yamashita and Osterle, 1995; Zheng et al., 1997). In particular, some neuroepithelial cells require both F GF -2 and I GF -I for progression through

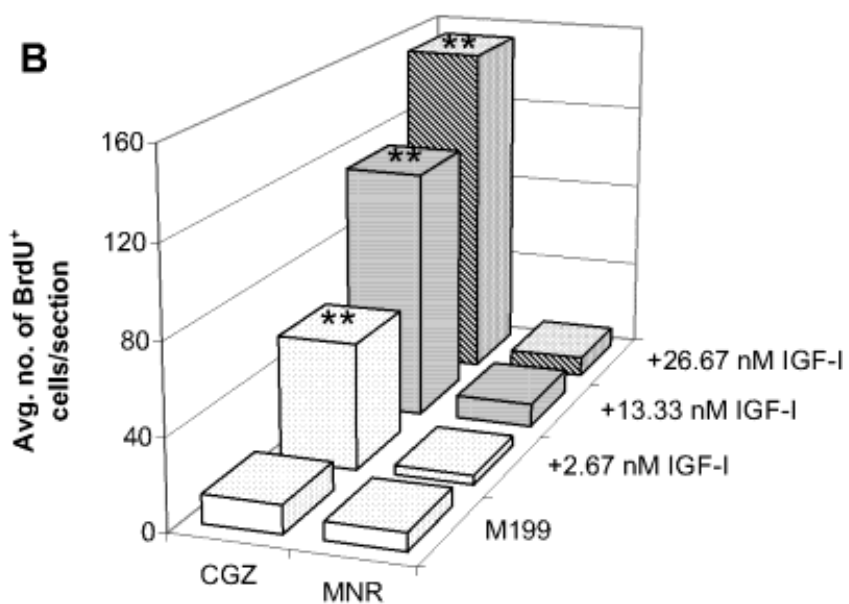

example of the data for the non-insulin-related peptides, $10 \mathrm{nM}$ fibroblast growth factor 2 (FGF-2). B: Illustrates the dose-response relationship between the average number of $\mathrm{BrdU}^{+}$cells and the concentration of IGF-I. Double asterisks indicate **P $<0.005$. CGZ, circumferential germinal zone; MNR, mature neural retina.

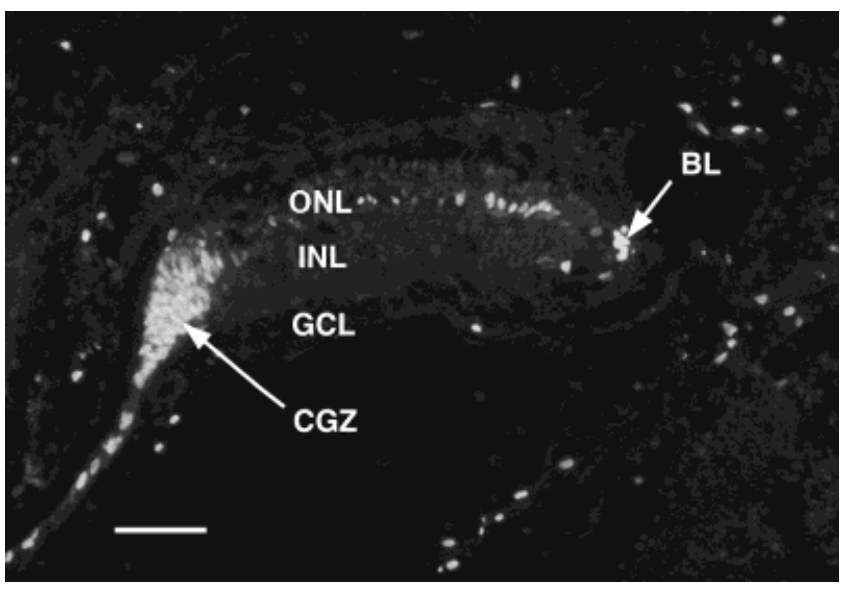

Fig. 3. Low-magnification, fluorescence photomicrograph of a section from a retina that was lesioned and treated in vitro with insulin-like growth factor I (IGF-I). Note the presence of injuryinduced, bromodeoxyuridine positive $\left(\mathrm{BrdU}^{+}\right)$cells in the outer nuclear layer (ONL; cf. Figs. 3 and $1 \mathrm{~B}$ ) and blastema and the enlarged circumferential germinal zone. INL, Inner nuclear layer; GCL, ganglion cell layer; CGZ, circumferential germinal zone; BL, blastema. Scale bar $=50 \mu \mathrm{m}$

the cell cycle (Drago et al., 1991; see also Pons and Torres-Alemán, 1992; F rödin and Gammeltoft, 1994). Based upon these data and the absence of a consistent response by the rod precursors or injury-induced retinal progenitors to growth factors tested individually, FGF-2 and IGF-I were tested on retinas with lesions al one at single, moderate concentrations and in combination. In retinas treated with F GF -2 at 7.5 nM there was no significant difference in the number of $\mathrm{BrdU}^{+}$cells, as compared with control retinas, in any of the areas examined (Fig 5 ). In retinas treated with $15 \mathrm{nM} \mathrm{IGF-I,} \mathrm{the} \mathrm{number} \mathrm{of} \mathrm{BrdU}{ }^{+}$cells in the proximal CGZ and distal CGZ was four-fold and nine-fold greater than controls, respectively. Again, there was no significant difference in the number of BrdU + cells in the proximal MNR, distal MNR or blastema (Fig. 5). In retinas treated with a combination of $7.5 \mathrm{nM} \mathrm{FGF-2}$ and 15 nM IGF-I, the number of BrdU + cells in the proximal CGZ 


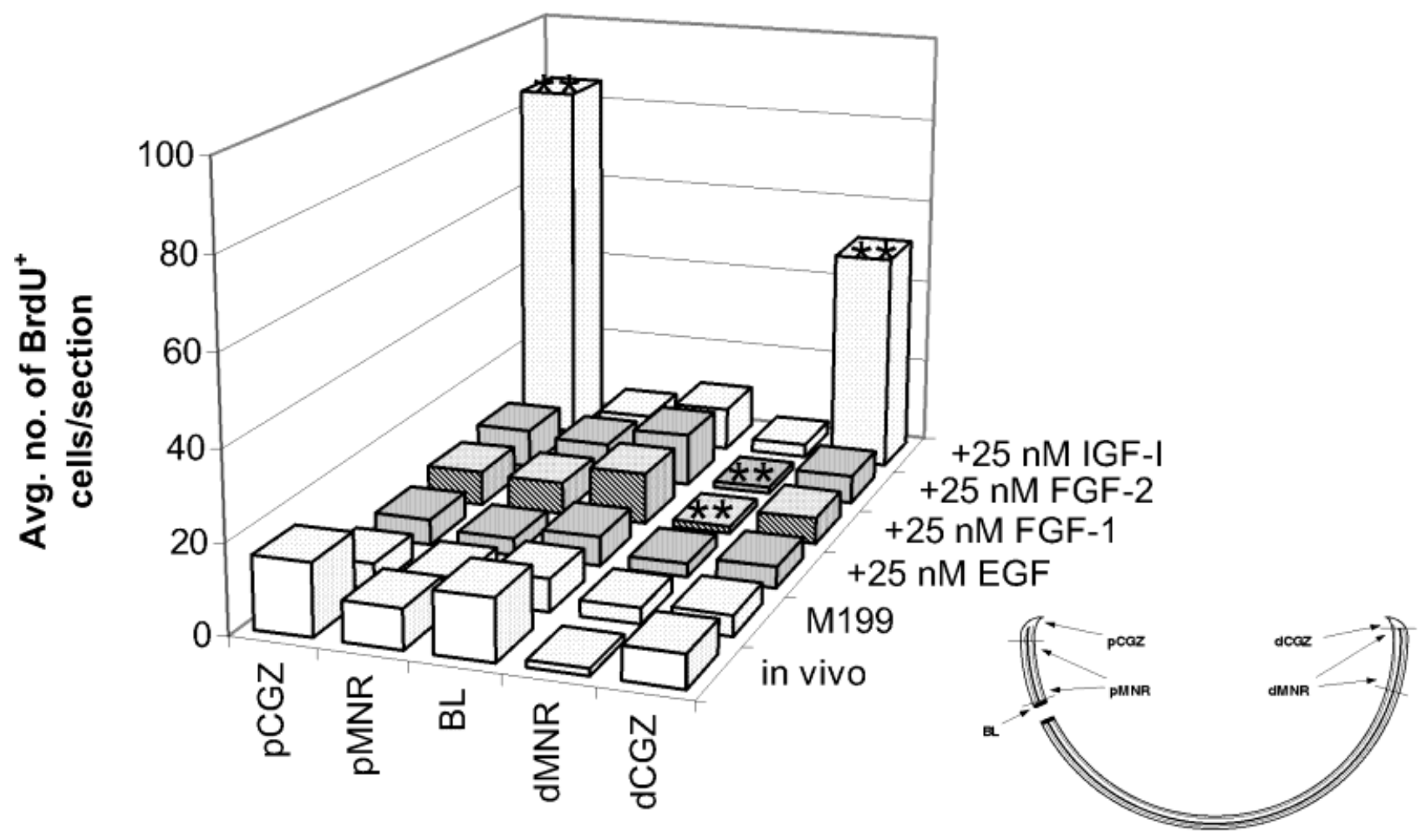

Fig. 4. Histograms illustrating the average number of bromodeoxyuridine positive $\left(\mathrm{BrdU}^{+}\right)$cells per section in retinas with lesions. Note the generally larger values for the circumferential germinal zone and mature neural retina proximal to the blastema, as compared to the distal sites (see text). Insulin-like growth factor I (IGF-I) and insulin (not shown) stimulated a large increase in the average number of $\mathrm{BrdU}^{+}$cells in the circumferential germinal zone only. Inset: Diagram

and distal CGZ was four-fold and seven-fold greater than controls, respectively, but there were no significant differences in the number of $\mathrm{BrdU}^{+}$cells in the MNR or blastema. Compared to retinas treated with IGF-I alone, the combination of FGF-2 and IGF-I did not significantly change the average number of $\mathrm{BrdU}+$ cells (F ig. 5), indicating the absence of a synergistic effect from the combination of these two peptides.

\section{DISCUSSION}

In this study, we tested a panel of peptide growth factors for their ability to stimulate proliferation of mitotically active neuronal progenitors in the retina of the adult goldfish. By design, each growth factor was tested in at least two independently controlled experiments. Of the factors tested, only insulin, IGF-I and IGF-II stimulated proliferation. This effect, however, was limited to the retinal progenitors within the CGZ. The rod precursors and injury-induced retinal progenitors of the blastema did not increase their proliferation in response to any of the growth factors tested.

At the outset of this study, a concern was the use of mammalian growth factors to stimulate proliferation of teleost cells. Although some of the factors we tested are present in fish (e.g., see Lagente et al., 1986; Rubinson, 1991; Raymond et al., 1992; Chan et al., 1993; Plisetksaya et al., 1993; Götz et al., 1994; Suzuki et al., 1994), we used mammalian growth factors because of their commercial availability, thegeneral unavailability of isolated or recom- of a retinal section indicating the approximate location of the lesion, and blastema and regions where BrdU + cells were counted. pCGZ, Proximal circumferential germinal zone; pMNR, proximal mature neural retina; $\mathrm{BL}$, blastema; $\mathrm{dMNR}$, distal mature neural retina; dCGZ, distal circumferential germinal zone. Double asterisks indicate $* * P<0.005$.

binant piscine growth factors and the demonstrated activity of mammalian growth factors on cells derived from teleosts. Heterologous assays have shown that mammalian growth factors are able to stimulate a broad range of responses in cells and tissues derived from teleosts. For example, bovine F GF -2 stimulates proliferation of cells in embryonic zebrafish (Bradford et al., 1994); murine EGF promotes survival of liver epithelial cells from zebrafish (Bradford et al., 1994); human EGF stimulates protein synthesis in salmon hepatocytes (Duan et al., 1993); human insulin increases serum levels of IGF-I in the marine teleost, gilthead seabream (Funkenstein et al., 1989); murine EGF and human TGF $\alpha$ bind to ovarian membranes from goldfish and stimulate oocyte meiosis (Patti et al., 1996); mammalian TGF, insulin, IGF-I and IGF-II are mitogenic for embryonic cells from zebrafish and trout (Collodi and Barnes, 1990); recombinant bovine insulin stimulates body growth in the isletectomized goby (Kelley et al., 1993); mammalian IGF-I stimulates sulfation in oral cartilage explants from fish (e.g., Duan and Hirano, 1990; Kelley et al., 1993); and mammalian NGF enhances axonal outgrowth from retinal explants from goldfish (Turner et al., 1980; Yip and Grafstein, 1982). Collectively, these data indicate the structure and function of peptide growth factors and their receptors are highly conserved between mammals and teleosts, and suggest therefore, the use of mammalian growth factors in an attempt to identify growth factors that modulate proliferation in the retina of the goldfish is a valid approach. 


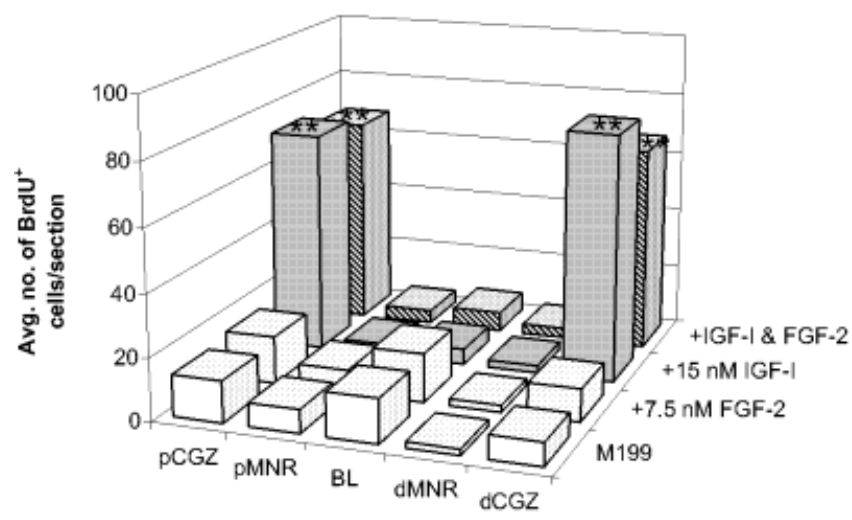

Fig. 5. Histograms illustrating theaverage number of bromodeoxyuridine positive $\left(\mathrm{BrdU}^{+}\right)$cells per section in retinas treated with M-199 alone, M-199 supplemented with fibroblast growth factor 2 (FGF-2), M-199 supplemented with insulin-like growth factor I (IGFI), and M-199 supplemented with a combination of F GF-2 and IGF-1. FGF-2 alone did not increase or decrease the number of BrdU+ cells. FGF-2 and IGF-I in combination did not increase the number of BrdU + cells above that seen with I GF-I alone. pCGZ, Proximal germinal zone; pMNR, proximal mature neural retina; $B L$, blastema; dMNR, distal mature neural retina; dCGZ, distal circumferential germinal zone. Double asterisks indicate ${ }^{* *} \mathrm{P}<0.05$.

The relative concentrations of insulin, IGF-I, and IGF-II that stimulated proliferation suggest that the retinal progenitors in the CGZ possess receptors specific for both insulin and IGF-I. IGF-I was more potent than insulin, however, the response to each was similar in magnitude and both stimulated proliferation at concentrations as low as $1 \mathrm{nM}$. Although we have no insight into the role played by IGF-I binding proteins in our assay, if the activity of insulin and IGF-I were mediated through a single receptor (either the insulin or IGF -I receptor; there are thought to be no IGF-II receptors in fish; Drakenberg et al., 1993), there should have been distinct differences in the effective concentrations due to the well known differences in the binding affinities of insulin and IGF-I to heterologous receptors (e.g., Gutierrez et al., 1995). It is assumed that in the developing brain IGF-II actions are mediated via the IGF-I receptor, and the relatively high concentrations of IGF-II required to stimulate proliferation is consistent with this assumption.

If receptors for both insulin and IGF-I are expressed by the retinal progenitors of the CGZ, different routes are utilized for delivering their respective ligands. IGF-I and IGF-II are synthesized in nervous tissue and are thought to mediate their signaling functions by both paracrine and autorcrine mechanisms (D'E rcole et al., 1996). I n contrast, insulin is synthesized in the pancreas, not the brain (e.g., Plisetskaya et al., 1993), and is believed to be delivered via the blood supply. This implies that the levels of insulin, IGF-I, and IGF-II within the retina are regulated differentially and these peptides may, therefore, play different roles in regulating neurogenesis in the goldfish retina.

In the goldfish, the progenitors within the CGZ give rise to all retinal cell types, including rod precursors. These progenitors are the remnants of the embryonic retinal neuroepithelium, and throughout the life of the animal generate neurons that are appended, in a seamless manner, to the existing retina. The molecular events that regulate neurogenesis within the CGZ of the adult goldfish retina are thought to be equival ent to those in the embryo (see Hitchcock et al., 1996). The robust proliferation of the retinal progenitors stimulated by insulin, I GF -I, and IGF-II is consistent with this notion. Insulin-related molecules are present in the retinas of embryonic birds and mammals, and in vitro can stimulate proliferation, differentiation, and neuronal maturation (e.g., Hansson et al., 1989; Lee et al., 1992; de la Rosa et al., 1994; HernándezSánchez et al., 1995; Tesoriere et al., 1995; Calvaruso et al., 1996; Frade et al., 1996; see reviews by de Pablo and de la Rosa, 1995; D'Ercole et al., 1996). Recent studies suggest that in the retina IGF-I and IGF-II regulate proliferation and neurogenesis, whereas insulin regulates cellular differentiation and maturation (Calvaruso et al., 1996; Frade et al., 1996; see Puro and Agardh, 1984; Hausman et al., 1991).

The complete lack of a mitotic response by the rod precursors and injury-induced retinal progenitors to any of the growth factors tested is subject to multiple interpretations. The simplest interpretation, of course, is that none of the peptides tested are mitogenic for these cells. Alternatively, some of the growth factors tested may be mitogenic for the rod precursors and injury-stimulated retinal progenitors of the blastema, but the culture technique or condition of the retina may not have been adequate to reveal this. F or example, the factors tested may have had only limited access to the mitotically active cells or endogenous factors may have been present in the retina at saturating levels. The possibility of limited access is of concern with respect to the rod precursors, because unlike the cells of the CGZ, they are distant from the inner surface of the retina, embedded in the outer nuclear layer, and as a consequence, may lie behind a barrier to the diffusion of exogenous molecules. Consistent with this possibility, insulin and IGF-I have been shown to stimulate proliferation of rod precursors in organotypic retinal slices from the cichlid fish Haplocromis burtoni (Mack and Fernald, 1993; see below). The possibility that endogenous growth factors are present at saturating levels is a concern with respect to the retinas with lesions. In mammals, penetrating injuries to the brain elicit local synthesis and release of growth factors, including IGF-I (Breese et al., 1996 and citations therein) and FGF-2 (Gomez-Panilla and Cotman, 1992). A large upregulation of the synthesis of a growth factor within the area of the retinal lesion may effectively mask the effects of any exogenous molecule on the injury-induced retinal progenitors. If mitotic activity is maximally stimulated by an endogenous factor, any exogenous factor, regardless of its concentration, would not stimulate additional cell division. I rrespective of the explanation for the negative results, it must be kept in mind, however, that the cellular response assayed here, cell division, is only one potential outcome of stimulating an intracellular signaling pathway by the binding of a growth factor to its receptor. The lack of mitotic stimulation by the various growth factors does not imply that these factors do not play a role in rod cell production or injury-stimulated neuronal regeneration.

Previous studies have attempted to identify molecules that modulate proliferation of retinal progenitors in the tel eost fish. U sing organotypic retinal slices in vitro, Mack and F ernald (1993) found that insulin and I GF -I stimulate the prol iferation of rod precursors in the retina of Haplocromis (these investigators did not comment on whether or not insulin and IGF-I stimulated proliferation among cells in the CGZ). The addition of FGF-2 to these cultures did not stimulate proliferation, but did increase the number of 
rod photoreceptors that became post-mitotic in culture. It was concluded that in Haplocromis insulin and IGF-I are mitogenic for the rod precursors, whereas F GF -2 acts as a differentiation factor. Negishi and Shinagawa (1993) found that intraocular injections of interleukin-6, phytohaemoagglutinin, FGF-1, and FGF-2 in the goldfish stimulated proliferation of rod precursors, as evidenced by an increase in the number of cells expressing the proliferating cell nuclear antigen. Based upon their potency, it was concluded that FGF -1 and -2 are native to the goldfish retina and regulate division by the rod precursors, and by extension, stimulate proliferation of these cells during retinal regeneration. These data (Mack and Fernald 1993; Negishi and Shinagawa, 1993) and our own are not in agreement. Like Mack and Fernald (1993), we found that insulin-related molecules are mitogenic for neuronal progenitors in fish, but only for the retinal progenitors of the CGZ, not the rod precursors. Unlike Negishi and Shinagawa (1993), we found none of the mititocally active cells in the retina were responsive to the fibroblast growth factors. Unfortunately methodological differences between the three studies make direct comparisons problematic. Intraocular injections is more similar to our experiments than organotypic slices, but this method can produce potentially confounding results, because ocular injuries that do not directly involve the retina can stimulate proliferation of rod precursors (Hitchcock, unpublished observation; see also Henken and Yoon, 1989). Resolving the disparate results of these three studies and, more importantly, identifying the signaling molecules that participate in the continual growth and regeneration of the tel eost retina will requirefurther investigation.

In considering all the data, the most parsimonious interpretation of the results of our study is that the retinal progenitors within the CGZ have receptors for insulin and IGF-I, and, therefore, in vivo insulin-related peptides, perhaps including IGF-II, regulate the mitotic activity of these cells. Because of their ubiquitous presence and pliotropic effects in the developing brain (see de Pablo and de la Rosa, 1995) and their known roles in regulating retinal neurogenesis (e.g., Frade et al., 1996), we have chosen to further investigate IGF -I and the IGF-I receptor in the retina of the goldfish. Based on the present results and the presumption that IGF-I in the brain acts by both autocrine and paracrine mechanisms, we hypothesize that IGF-I is expressed by cells in the goldfish retina and the IGF-I receptor is expressed by the retinal progenitors of the CGZ. In the following paper, we describe experiments where this hypothesis is tested, in part.

\section{ACKNOWLE DGMENTS}

The authors thank Drs. C. Duan and A. D'Costa and Ms. D. Otteson for critically reading earlier versions of this paper, Drs. D. Musch and K. Guire for help with the statistical analyses, P. Cirenza and M. Gillett for technical assistance, and D. Giebel for secretarial assistance.

\section{LITERATURE CITE D}

Anchan, R.M., T.A. Reh, J . Angello, A. Balliet, and M. Walker (1991) EGF and TGF $-\alpha$ stimulate retinal neuroepithelial cell proliferation in vitro. Neuron 6:923-936.

Anchan, R. and T. Reh (1995) Transforming growth factor $\beta-3$ is mitogenic for rat retinal progenitor cells in vitro. J . Neurobiol . 28:133-145.

Boucher, S.-E.M. and P.F. Hitchcock (1994a) Proliferation of neuronal precursors in the mature goldfish retina in vitro. Invest. Ophthalmol. Vis. Sci. (suppl.) 35:1512.
Boucher, S.-E.M. and P.F. Hitchcock (1994b) Insulin-like growth factor 1 (IGF-1) stimulates proliferation of neuronal progenitors in the retina of the goldfish. Soc. Neurosci. 20:1322.

Boucher, S.-E.M. and P.F. Hitchcock (1995) Insulin-related factors stimulate in vitro proliferation of pluripotent neuroepithelial cells, but not rod precursors or injury-induced progenitors, in adult goldfish retina. Soc. Neurosci. 21:1557.

Bradford, C., S.L. Sun, P. Collodi, and D.W. Barnes (1994) Cell cultures from zebrafish embryos and adult tissues. J. Tiss. Culture Meth. 16:99-107.

Breese, C.R., A. D'Costa, Y.D. Rollins, C. Adams, R.M. Booze, W.E. Sonntag, and S. Leonard (1996) Expression of insulin-like growth factor -1 (IGF-1) and IGF-binding protein 2 (IGF-BP2) in the hippocampus following cytotoxic lesion of the dentate gyrus. J. Comp. Neurol. 369:388-404.

Calvaruso, G., R. Vento, M. Giuliano, M. Lauricella, E. Gerbino, and G. Tesoriere (1996) Insulin-like growth factors in chick embryo retina during development. Regul. Pept. 61:19-25.

Chan, S.J ., Q.-P. Cao, S. Nagamatsu, and D.F. Steiner (1993) Insulin and insulin-like growth factor genes in fishes and other primitive chordates. In P.W. Hochachka and T.P. Mommsen (eds): Biochemistry and Molecular Biology of Fishes, vol. 2. Elsevier Scientific, pp. 407-417.

Collodi, P. and D.W. Barnes (1990) Mitogenic activity from trout embryos. Proc. Natl. Acad. Sci. USA 87:3498-3502.

D'Ercole, J .A., Y. Ping, A.S. Calikoglu, and G. Gutierrez-Ospina (1996) The role of insulin-like growth factors in the central nervous system. Mol. Neurobiol. 13:227-255.

de Pablo, F. and E. J . de la Rosa (1995) The devel oping CNS: a scenario for the action of proinsulin, insulin and insulin-like growth factors. Trends Neurosci. 18:143-150.

de la Rosa, E.J ., C.A. Bondy, C. Hernández-Sánchez, X. Wu, J. Zhou, A. López-Carranza, L.M. Scavo, and F. de Pablo (1994) Insulin and insulin-like growth factor system components gene expression in the chicken retina from early neurogenesis until late development and their effects on neuroepithelial cells. Euro. J . Neurosci. 6:1801-1810.

Drago, J ., M. Murphy, S.M. Carroll, R.P. Harvey, and P.F. Bartlett (1991) Fibroblast growth factor-mediated proliferation of central nervous system precursors depends on endogenous production of insulin-like growth factor I. Proc. Natl. Acad. Sci. USA 88:2199-2203.

Drakenberg, K., V.R. Sara, S. Falkmer, S. Gammeltoft, C. Maake, and M. Reinecke (1993) Identification of IGF-1 receptors in primitive verte brates. Regul. Pept. 43:73-81.

Duan, C. and T. Hirano (1990) Stimulation of ${ }^{35}$ S-sulfate uptake by mammalian insulin-like growth factor I and II in cultured cartilages of the J apanese eel, Anguilla japonica. J . Exp. Zool. 256:347-350.

Duan, C., Y. Takeuchi, N. Hanzawa, and S. Miyachi (1993) Epidermal growth factor stimulates protein synthesis in primary cultures of salmon hepatocytes. Gen. Comp. Endocrinol. 90:383-388.

Easter, S.S., J r., P.R. J ohns, and L.R. Baumann (1977) Growth of the adult goldfish eye. I. Optics. Vision Res. 17:469-477.

Frade, J.M., E. Martí, P. Bovolenta, M. Ángeles Rodríguez-Peña, D. Pérez-Garcia, H. Rohrer, D. Edgar, and A. Rodríguez-Tébar (1996) Insulin-like growth factor-I stimulates neurogenesis in chick retina by regulating expression of the $\alpha 6$ integrin subunit. Devel opment 122:24972506.

Frödin, M. and S. Gammeltoft (1994) Insulin-like growth factors act synergistically with basic fibroblast growth factor and nerve growth factor to promote chromaffin cell proliferation. Proc. Natl. Acad. Sci. USA 91:1771-1775.

Funkenstein, B., A. Silbergeld, B. Cavari, and Z. Laron (1989) Growth hormone increases plasma levels of insulin-like growth factor (IGF-I) in a teleost, the gilthead seabream (Sparus aurata). J . Endocrinol. 120: R19-21.

Gomez-Pinilla, F. and C. Cotman (1992) Transient lesion-induced increase of basic fibroblast growth factor and its receptor in layer $\mathrm{VIb}$ (subplate cells) of the adult rat cerebral cortex. Neurosci. 49:771-780.

Götz R., R. Koster, C. Winkler, F. Raulf, F. Lottspeich, M. Schartl, and H. Theonen (1994) Neurotrophin-6 is a new member of the nerve growth factor family. Nature 372:266-269.

Gutierrez, J ., M. Parrizas, M.A. Maestro, I. Navarro, and E.M. Plisetskaya (1995) Insulin and IGF-I binding and tyrosine kinase activity in fish heart. J . Endocrinol. 146:35-44.

Hansson, H.A., A. Holmgren, G. Norstedt, and B. Rozell (1989) Changes in the distribution of insulin-like growth factor I, thioredoxin, thioredoxin reductase and ribonucleotide reductase during the development of the retina. Exp. Eye. Res. 48:411-420. 
Hausman, R.E., G.D. Sagar, and B.H. Shah (1991) Initial cholinergic differentiation in embryonic chick retina is responsive to insulin and cell-cell interactions. Dev. Brain Res. 59:31-37.

Henken, D.B. and M.G. Yoon (1989) Optic nerve crush modulates proliferation of rod precursor cells in the goldfish retina. Brain Res. 501:247259.

Hernández-Sánchez, C., A. López-Carranza, C. Alarcón, E.J . de la Rosa and F. de Pablo (1995) Autocrine/paracrine role of insulin-related growth factors in neurogenesis: Local expression and effects on cell proliferation and differentiation in retina. Proc. Natl. Acad. Sci. USA 92:9834-9838.

Hitchcock, P.F. and P.A. Raymond (1992) Retinal regeneration. Trends Neurosci. 15:103-108.

Hitchcock, P.F., K.J . Lindsey Myhr, S.S. Easter, J r., R. Mangione-Smith, and D. Dwyer J ones (1992) Local regeneration in the retina of the goldfish. J . Neurobiol . 23:187-203.

Hitchcock, P.F., R.E. Macdonald, J .T. VanDeRyt, and S.W. Wilson (1996) Antibodies against pax 6 immunostain amacrine and ganglion cells and neuronal progenitors, but not rod precursors, in the normal and regenerating retina of the goldfish. J . Neurobiol. 29:399-413.

J ohns, P.R. (1977) Growth of the goldfish eye. III. Source of new retinal neurons. J . Comp. Neurol. 176:343-357.

J ohns, P.R. and R.D. Fernald (1981) Genesis of rods in teleost fish. Nature 293:141-142.

Kelley, K.M., E.S. Gray, K. Shiharath, C.S. Nicoll, and H.A. Bern (1993) Experimental diabetes mellitus in a teleost fish. II. Roles of insulin, growth hormone $(\mathrm{GH})$, insulin-like growth factor-I and hepatic $\mathrm{GH}$ receptors in diabetic growth inhibition in the goby, Gillichthys mirabilis. Endocrinology. 6:2696-2702.

Lagente, O., M. Diry, and Y. Courtois (1986) Isolation of heparin-binding growth factors from dogfish (Mustela canis) brain and retina. FEBS Lett. 202:207-210.

Lee, W.-H., S. J avedan, and C.A. Bondy (1992) Coordinate expression of insulin-like growth factor system components by neurons and neurogl ia during retinal and cerebellar development. J . Neurosci. 12:4737-4744.

Leibush, B., M. Parrizas, I. Navarro, Y. Lappova, M.A. Maestro, M. Encinas, E.M. Plisetskaya, and J. Gutiérez (1996) Insulin and insulinlike growth factor-I receptors in fish brain. Regul. Pept. 61:155-1561.

Lillien, L. and C. Cepko (1992) Control of proliferation in the retina: temporal changes in responsiveness to FGF and TGF- $\alpha$. Development 115:253-266.

Mack, A.F. and R.D. Fernald (1993) Regulation of cell division and rod differentiation in the teleost retina. Dev. Brain Res. 76:183-187.

Mack, A.F., S.L. Balt, and R.D. Fernald (1995) Localization and expression of insulin-like growth factor in the teleost retina. Vis. Neurosci. 12:457-461.

Meyer, R.L. (1978) Evidence from thymidine labeling for the continuous growth of retina and tectum in juvenile goldfish. Exp. Neurol. 59:99111.

Negishi, K. and S. Shinagawa (1993) Fibroblast growth factor induces proliferating cell nuclear antigen-immunoreactive cells in goldfish retina. Neurosci. Res. 18:143-156.

Patti, D., K. Balshaw, D.L. Grinwich, M.D. Hollenberg, and H.R. Habibi (1996) E pidermal growth factor receptor binding and biological activity in the ovary of goldfish, Carassius auratus. Am. J . Physiol. 270:R10651072.

Plisetksaya, E.M., V.M. Bondareva, C. Duan, and S.J . Duguay (1993) Does salmon brain produce insulin? Gen. Comp. Endocrinol. 91:74-80.

Pons, S. and I. Torres-Alemán (1992) Basic fibroblast growth factor modulates insulin-like growth factor-I, its receptor, and its binding proteins in hypothalamic cell cultures. Endocrinology 131:2271-2278.

Puro, D.G. and E. Agardh (1984) Insulin-mediated regulation of neuronal maturation. Science 225:1170-1172.

Raymond, P.A., L.K. Barthel, and M.E. Rounsifer (1992) Immunolocalization of basic fibroblast growth factor and its receptor in adult goldfish retina. Exp. Neurol. 115:73-78.

Raymond, P.A., M.J . Reifler, and P.K. Rivlin (1988) Regeneration of the goldfish retina: Rod precursors are a likely source of regenerated cells. J. Neurobiol. 19:431-463.

Raymond, P.A. and P.F. Hitchcock (1997) Retinal regeneration: Common principles but a diversity of mechanisms. Advances Neurobiol. 72:171184.

Rubinson, K. (1991) Distribution of basic fibroblast growth factor in developing lamprey retina. Invest. Ophthalmol. Vis. Sci. (suppl.) 32 1299.

Suzuki, T., T. Kurokawa, and M. Asashima (1994) Identification of a heparin-binding, mesoderm-inducing peptide in the swim-bladder of the red seabream, Pagrus major: A probable fish fibroblast growth factor. Fish Physiol. Biochem. 13:343-352.

Tesoriere, G., R. Vento, V. Morello, R.M. Tomasino, M. Carabillo, and M. Lauricella (1995) Chick embryo retina development in vitro: The effect of insulin. Neurochem. Res. 20:803-813.

Turner, J .E., R.K. Delaney, and J .E. J ohnson (1980) Retinal ganglion cel response to nerve growth factor in the regenerating and intact visual system of the goldfish (Carassi us auratus). Brain Res. 197:319-330.

Yamashita, H. and E.C. Osterle (1995) Induction of cell proliferation in mammalian inner-ear sensory epithelia by transforming growth factor $\alpha$ and epidermal growth factor. Proc. Natl. Acad. Sci. USA 92:31523155.

Yip, H.K. and B. Grafstein (1982) Effect of nerve growth factor on regeneration of goldfish optic axons. Brain Res. 238:329-339.

Zheng, J .L., C. Hel big, and W.-Q. Gao (1997) Induction of cell proliferation by fibroblast and insulin-like growth factors in pure rat inner ear epithelial cell cultures. J . Neurosci. 17:216-226. 